\title{
GreenHP: Next Generation Heat Pump for Retrofitting Buildings - New Evaporator Component for Large Capacity Air-to-Water Heat Pumps
}

\author{
Christoph Reichl ${ }^{1}$, Andreas Strehlow ${ }^{2}$, Thore Oltersdorf ${ }^{3}$, Simon Braungardt ${ }^{3}$, Marco Pröhl ${ }^{4}$, Peter Benovsky $^{5}$, \\ Mirza Popovac ${ }^{6}$, Thomas Fleckl ${ }^{7}$, \\ 1,5,6,7 Austrian Institute of Technology $\mathrm{GmbH},{ }^{2} \mathrm{AKG}$ Verwaltungsgesellschaft, ${ }^{3}$ Fraunhofer-Institut \\ für Solare Energiesysteme ISE, ${ }^{4}$ Fraunhofer-Institut für Werkzeug- und Umformtechnik IWU
}

\begin{abstract}
Air to water heat pumps account by more than $70 \%$ for the main share of HP-systems of the European HP market. Retrofitting applications in particular show a very high potential for the $\mathrm{A} / \mathrm{W}$ heat pump technology. Innovative components will pave the way for the next generation heat pumps. In case of the evaporator, low refrigerant charge is introduced by using bionic distributors and evaporator icing is studied on several heat exchanger designs by using advanced experimental and numerical methods.
\end{abstract}

Keywords - Air-to-water heat pump, anti-icing, micro-channel tubes, refrigerant charge reduction

\section{INTRODUCTION}

The building sector is one of the key consumers of energy in Europe today with an overall rising trend over the past 20 years. To replace inefficient heating systems based on fossil fuels or direct electric heating, it is essential to renovate and retrofit these buildings. The proposed heat pump technology offers a solution to both present and future challenges. The goal of the GreenHP (www.greenhp.eu) project is to investigate and develop a new highly efficient heating system based on large capacity air-to-water heat pumps for retrofitting multi-family houses and commercial buildings with a focus on cities. This heat pump system will use the natural refrigerant propane (R290) and will interact with large (renewable) energy systems, like the smart grid in particular.

An important objective is the development of new components of large capacity heat pumps ready for commercialisation in the follow-up process of the project. A new compressor concept was developed specifically for R290, which is integrated in a holistic control strategy for most efficient energy management with minimized oil charge to reduce refrigerant charge. The use of aluminium micro-channel tubes in the condenser allows an improved heat exchange compared to conventional steel designs in brazed plate heat exchangers and a significant weight reduction. It is important to provide sufficient corrosion stability by usage of advanced aluminium alloys.

On the air side of the evaporator, highly efficient air fins were developed that are less sensitive to icing and easy to defrost. This was achieved by applying advanced numerical (CFD and ice aggregation simulations) and experimental (image capturing and transient mass acquisition) approaches. The simulations are based on fundamental principles of energy and mass conservation. In the frost layer, a quasi-steady and uniform distribution is assumed and the mass transfer implementation has been based on the Lewis analogy. The simulations have been used in the parametric study of the evaporator fin design with respect to the frosting characteristics. The obtained results allowed for a better insight into the temporal and spatial frost distribution and related parameters that are the most influential, which guided the evaporator design towards the optimal frosting configuration. Special attention had to be paid to the acquisition and analysis of the mass signals recorded in the ice aggregation process, as the turbulent air flow and vibrations introduced by the coolant lead to highly fluctuating mass signals. Furthermore, the fan was optimised for better handling of icing conditions as well as minimized noise production by a combined sizing of evaporator and fan.

On the propane side of the evaporator a novel approach was used, utilizing a bionic distributor to evenly load the microchannel tubes with constant vapor qualities of the refrigerant. An algorithm was developed based on reliable flow regime maps to reach symmetrical flow conditions at each bifurcation with controlled mass fluxes and vapor qualities and void fractions, respectively. Starting from the feeding line at the outlet of the expansion valve a binary bifurcation takes place up to all 64 passages of the evaporator. For the purpose of validation, there was a lack of appropriate two-phase pressure drop models for bends and bifurcations within the distributor. Therefore, in analogy to the air side, the experimental and numerical approaches were applied. Special attention was necessary for the manufacturing process to connect distributor and evaporator.

The innovative approaches on the air-side and propane side like a sound-reduced combination of evaporator and fan, an evaporative heat transfer allowing small refrigerant charges and a frost-resistant evaporator culminate in a highly interesting component development for future heat pump product developments.

\section{AIR-SIDE OF THE EVAPORATOR}

Both experimental and numerical methods have been used to characterize the icing behavior of cooled fin samples and small heat exchanger packages. Experimental methods are based on a small scale wind tunnel placed in a climate chamber. The wind 
tunnel is equipped with both global and local measurement devices described in detail in section II.A. Computational Fluid Dynamics (CFD) simulations are used for the analysis of the ice onset and growth under icing conditions on fin samples and HEX packages. These techniques are discussed in section II.B. In Air/Water Heat pumps the ice and frost formation has been studied by Albert et al. [6], defrost cycle performance has been investigated by Hewitt et al. [11] and Payne et al. [15]. Surface Coatings have also been visited in heat pumps [14]. In the field of tube heat exchanger, pure condensation phenomena have been analyzed by Browne et al. [7], Cavallini et al. [8], Fitzgerald et al. [10] and Marto [13] - icing on tubes by Cremaschi et al. [9] and Kollar et al. [12]. Wang et al. have worked extensively on heat transfer and friction in fin-and-tube heat exchangers (plate, wavy, louvered) [16]-[17].

\section{A. Experimental Methods}

A small scale wind tunnel was built to be set-up in the AIT climate chambers supporting typical cross sections (width $\mathrm{x}$ height) from $250 \times 30 \mathrm{~mm}^{2}$ to $344 \times 244 \mathrm{~mm}^{2}$. The wind tunnel is built as a modular setup in an open-loop configuration. Different devices can be examined in the test section allowing diagnostics of temperature, humidity, pressure and volume flow rate on the air-side and the measurement of temperature and volume flow rate on the coolant side. Mass growth of the fins and heat exchanger packages due to condensation and icing can be determined online: the devices are mounted on a scale which records mass growth during the icing process.

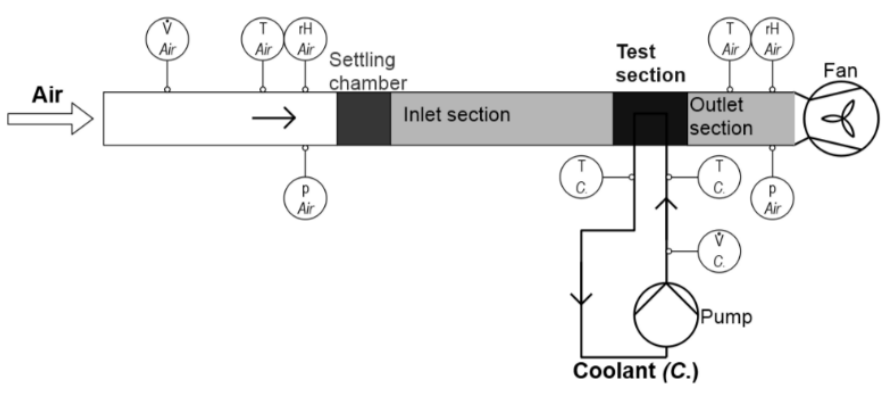

Fig. 1. AIT small scale wind tunnel. The modular set-up allows for easy exchange of different heat exchanger devices through an adaptable test section.

The wind tunnel and especially the test section is built out of transparent materials allowing for the application of optical measurement methods like particle image velocimetry (PIV) and image capturing techniques. Fig. 1 gives a schematic overview of the wind tunnel and the locations of global flow parameters, Fig. 2 shows the experimental setup placed in one of the climate chambers at AIT.

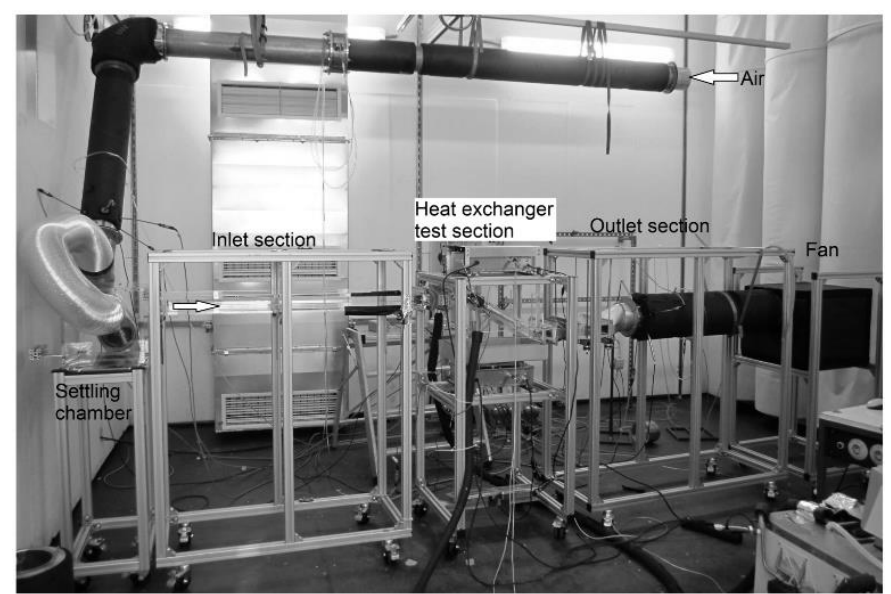

Fig. 2. Setup showing from left to right: settling chamber, inlet section, heat exchanger test section with scales, outlet section and the fan.

Particle Image Velocimetry measurements have been performed to access velocity maps in the middle of the wind tunnel - these measurements have been done without a sample in the test section and show a uniform flow distribution at the end of the inlet section - proving that anisotropic components introduced in the settling chamber have negligible influence on the test section. Constant Temperature Anemometry (CTA) measurements indicate only slight disturbances, if samples are placed in the test section (see Fig. 3).

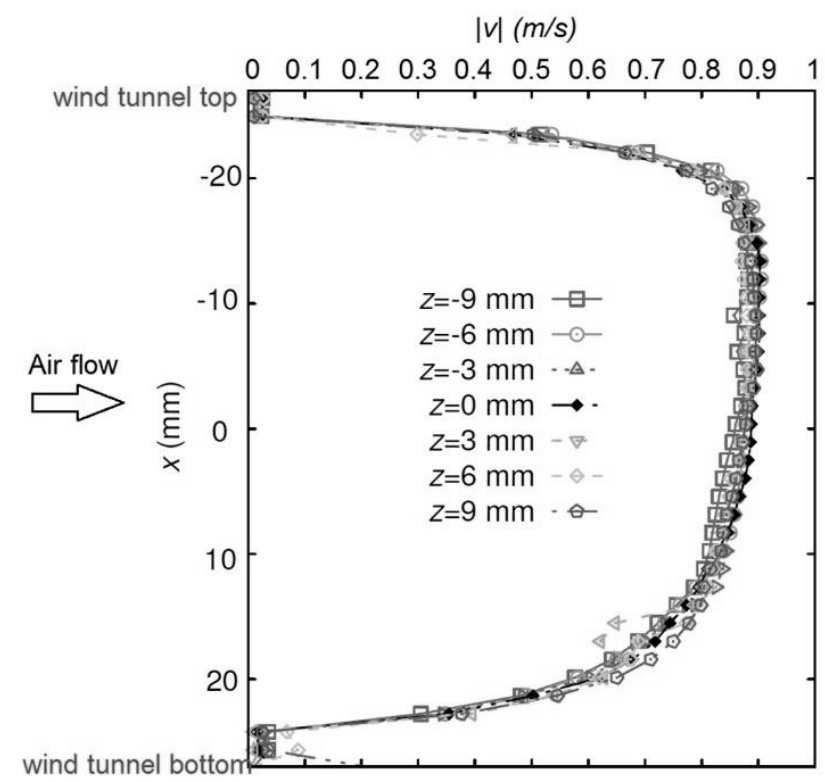

Fig. 3. Velocity profile for different distances along the width of the inlet section upstream of the test section.

\section{B. Experiments with fin samples}

Different fin samples (plain, wavy, lanced and louvered) with different heights and pitches have been investigated. These samples have been mounted in MPE tubes and cooled by coolant solution. Fig. 4 shows a typical fin sample and Fig. 5 gives an overview of the fin samples under investigation. 


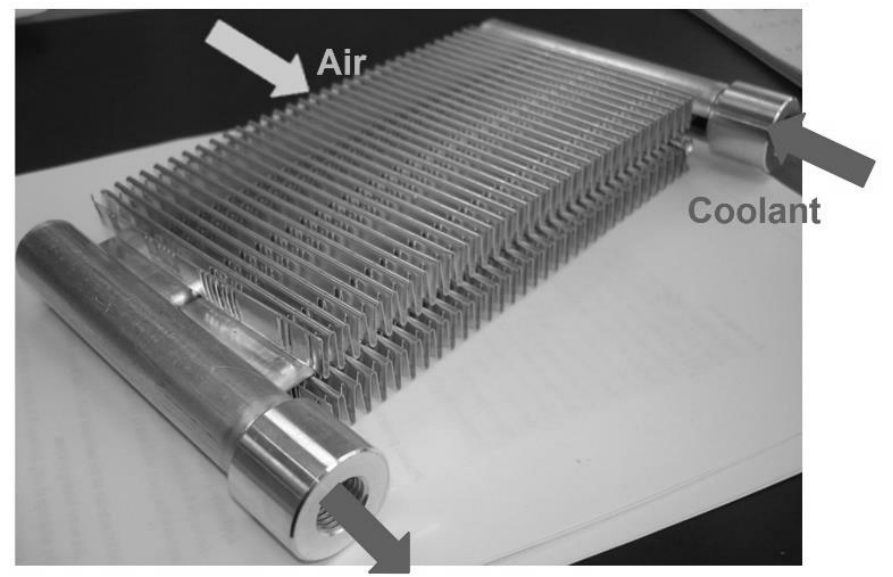

Fig. 4. Typical fin sample with wavy fins mounted on a MPE tube.

\begin{tabular}{|l|l|l|}
\hline Fin / Name of the sample & Height & Pitch \\
\hline Plain fin \#1 & $10,4 \mathrm{~mm}$ & $5,0 \mathrm{~mm}$ \\
\hline Plain fin \#2 & $10,4 \mathrm{~mm}$ & $10,0 \mathrm{~mm}$ \\
\hline Wavy fin \#1 & $10,4 \mathrm{~mm}$ & $5,0 \mathrm{~mm}$ \\
\hline Wavy fin \#2 & $10,4 \mathrm{~mm}$ & $8,0 \mathrm{~mm}$ \\
\hline Lanced fin \#1 & $10,0 \mathrm{~mm}$ & $4,8 \mathrm{~mm}$ \\
\hline Louvered fin \#1 & $10,4 \mathrm{~mm}$ & $5,3 \mathrm{~mm}$ \\
\hline
\end{tabular}

Fig. 5. Summary of fin samples placed in the test section of the small scale wind tunnel facility. All fins characterized by structure, height and pitch have been mounted on MPE tubes.

The experiments were performed by changing the set points of the coolant temperature. During icing, the inlet air was fixed at a temperature of $-0.8 \pm 0.4^{\circ} \mathrm{C}$ exhibiting a relative humidity of $71 \pm 2 \%$. The maximum volume flow rate was $62 \mathrm{~m}^{3} / \mathrm{h}$ which corresponds to a speed of $2.3 \mathrm{~m} / \mathrm{s}$. The coolant volume flow rate was kept at $0.65 \pm 0.01 \mathrm{1} / \mathrm{min}$. Figure 6 shows a typical icing and defrosting cycle.

During icing the air volume flow rate and the heat transfer decline, whereas the pressure difference over the fin samples increases. The time span, when the air volume flow rate has decreased from $100 \%$ to $75 \%$ of its start value has been defined as "icing time".

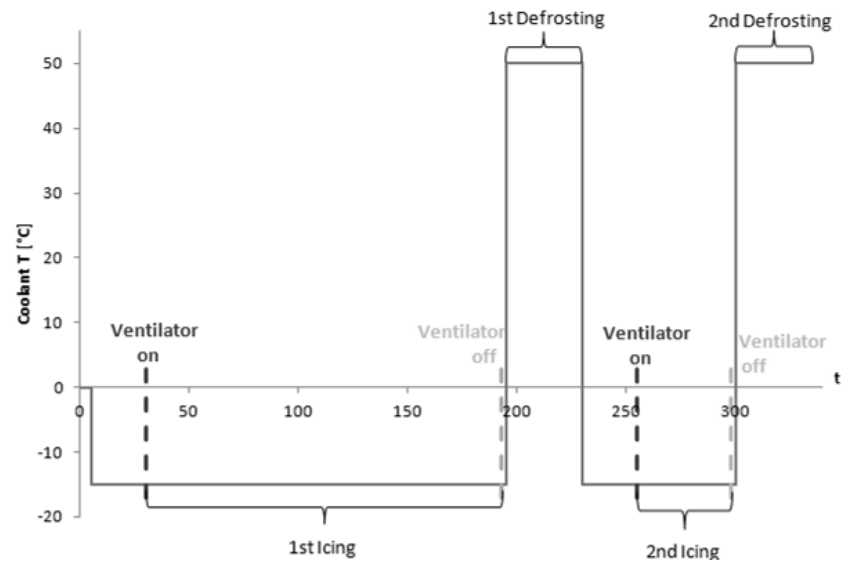

Fig 6. Typical icing and defrosting cycle showing the set point changes of the coolant liquid temperature versus time. Two defrosting stages are shown.

A mean heat transfer is calculated using

$\dot{Q}_{\text {mean }}=\frac{1}{t_{I C E}} \int_{0}^{t_{I C E}} \dot{Q}_{h e x} \cdot d t$

$Q_{\text {hex }}=V_{\text {coolant }} \cdot \rho_{\text {coolant }} \cdot c_{p, \text { coolant }}\left(I_{\text {out,coolant }}^{\prime}-I_{\text {in, coolant }}\right)$

Fig. 7 shows the heat transfer decrease during icing for a typical measurement using plain fin \#1 (see Fig. 5). The inlet air temperature was set to $-0.8{ }^{\circ} \mathrm{C}$ with a relative humidity of $70 \%$.

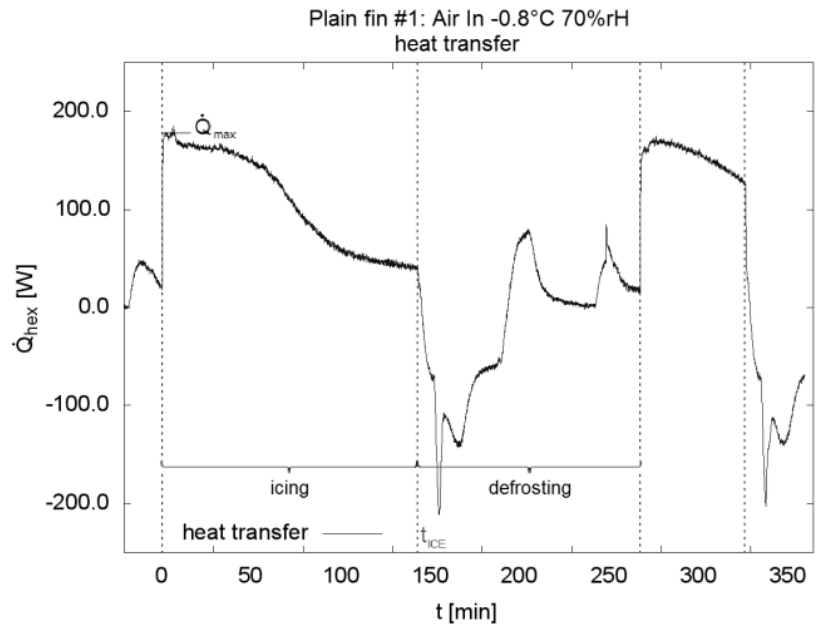

Fig. 7. Heat transfer decrease during icing.

During the experiments air pressure drops due to blocking of flow through the fins due to ice aggretion on the fin and MPE tube structures. Fig. 8 gives an example of absolute pressure and pressure drop during a typical icing experiment. 


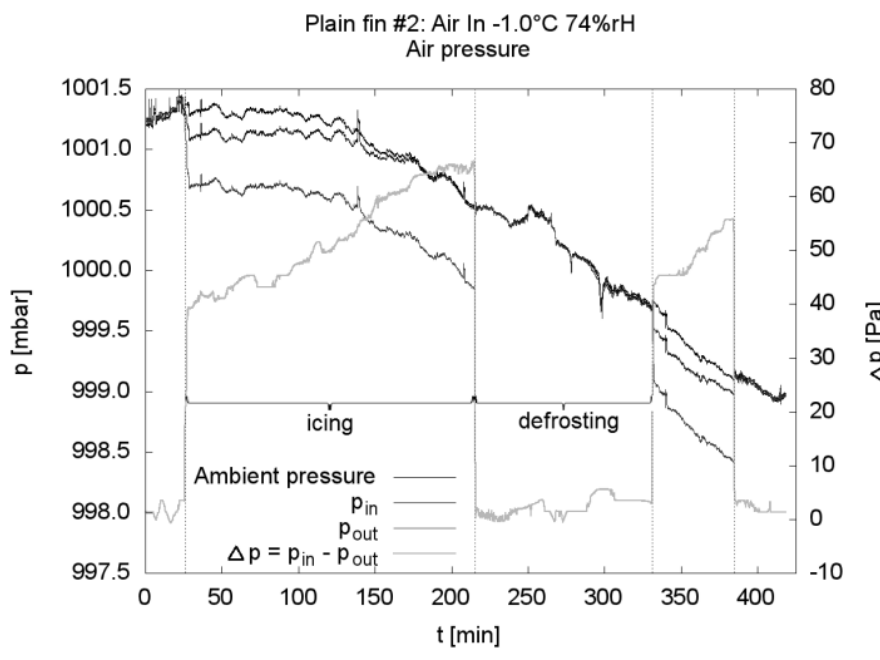

Fig 8. Absolute pressure (left scale, dark gray curves) and pressure difference (right scale, light gray curve) for a typical icing and defrosting experiment with plain fin \#2 (see Fig. 5).

Icing times and mean heat transfer are summarized in Fig. 9. Highest and lowest values are shown in gray. Icing time measurements are given with an error of around $20 \%$, the inaccuracy of the mean heat transfer calculation can be estimated to be around $8 \%$.

\begin{tabular}{|c|c|c|c|}
\hline \multicolumn{2}{|c|}{ ris } & \multicolumn{2}{|c|}{ Mean values } \\
\hline \multicolumn{2}{|c|}{ Fin / Name of the sample } & $t_{I C E}$ & $\dot{Q}_{\text {mean }}$ \\
\hline Plain fin \#1 & & $3059 \mathrm{~s}$ & $156 \mathrm{~W}$ \\
\hline Plain fin \#2 & & $4688 \mathrm{~s}$ & $104 \mathrm{~W}$ \\
\hline Wavy fin \#1 & & $2380 \mathrm{~s}$ & $166 \mathrm{~W}$ \\
\hline Wavy fin \#2 & & $3767 \mathrm{~s}$ & $135 \mathrm{~W}$ \\
\hline Lanced fin \#1 & & $1300 \mathrm{~s}$ & $163 \mathrm{~W}$ \\
\hline Louvered fin \#1 & & $1766 \mathrm{~s}$ & $167 \mathrm{~W}$ \\
\hline Plain/louvered fin \#1 & & $883 \mathrm{~s}$ & $117 \mathrm{~W}$ \\
\hline
\end{tabular}

Fig. 9. Icing times and heat transfer for various fin samples. Gray fields mark the highest and lowest values respectively.

Fins showing long icing times exhibit lower mean heat transfer compared to the other fins. Fins with equal geometry showed longer icing times, if their pitch was larger - in this case the heat transfer was also lower. Short icing times compared with good mean heat transfer can be seen in case of the louvered fin \#1 and the lanced fin \#1; a good balance between icing times and heat transfer has been found for wavy fins. These results led to the decision to focus on these fin structures for the small heat exchanger packages.

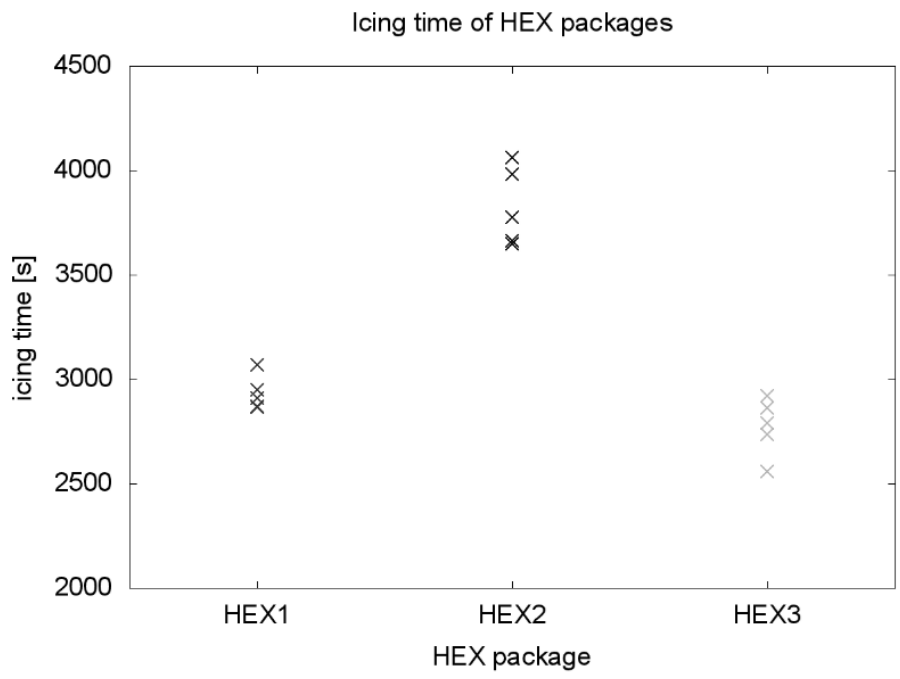

Fig. 10. Typical icing times for three wavy fin heat exchanger packages characterized by different heights, pitches and wave angles.

\section{Experiments with small heat exchanger packages}

Three different heat exchanger packages based on wavy fins pitch $5.0 \mathrm{~mm}$, height $10.4 \mathrm{~mm}$ (HEX1), pitch $5.0 \mathrm{~mm}$, height $11.3 \mathrm{~mm}$ (HEX2) and fin pitch $4.5 \mathrm{~mm}$, height $10.4 \mathrm{~mm}$ (HEX3)

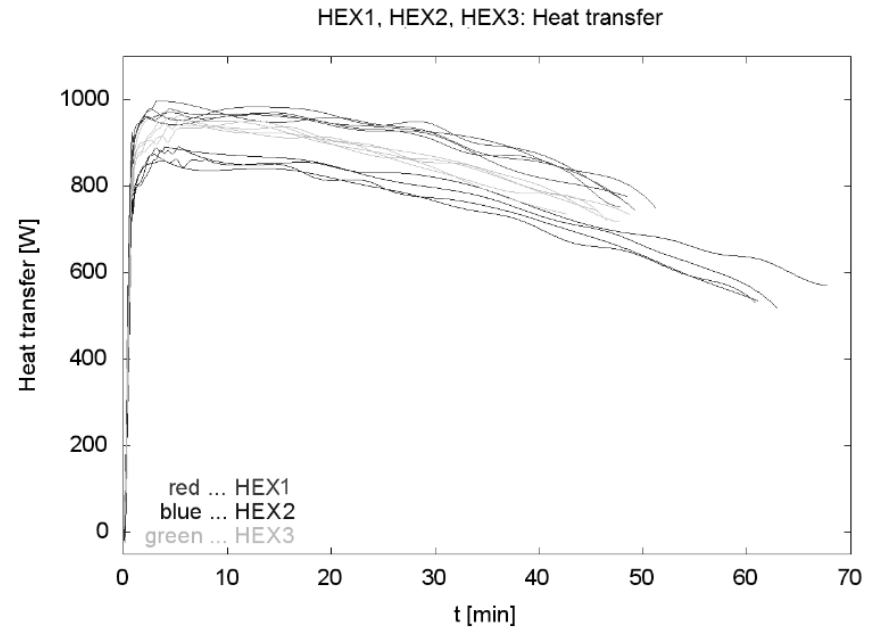

Fig. 11. Typical heat transfer for the three heat exchanger packages during several measurement runs.

have been built and measured in the wind tunnel facility. Inlet air temperature was set to $1.9 \pm 0.3{ }^{\circ} \mathrm{C}$ conditioned with a relative humidity of $73 \pm 2 \%$. A volume flow rate of a maximum of $335 \mathrm{~m}^{3} / \mathrm{h}$ for the air flow and $2.11 \pm 0.03 \mathrm{l} / \mathrm{min}$ for the coolant was used for the experiments.

Icing times and heat transfer defined as given in section B are shown in Fig. 10 and Fig. 11 respectively, their mean values 
given in Table 1. HEX1 and HEX3 show nearly the same icing time, HEX1 has a slightly higher mean heat transfer. HEX2 has a considerably longer icing time and mean heat transfer is lower by $\sim 100 \mathrm{~W}$. Since HEX2 has the greatest pitch and the smallest wave angle of the 3 geometries, this is in line with earlier experiments.

TABLE 1.

ICING TIME, MAXIMUM PRESSURE LOSS AND MEAN HEAT TRANSFER FOR THE THREE WAVY FIN HEAT EXCHANGER PACKAGES

\begin{tabular}{|c|c|c|c|}
\hline HEX & Icing time & Maximal $p$ loss & Mean heat transfer \\
\hline HEX1 & $2933 s \pm 84 s$ & $285 \mathrm{~Pa} \pm 3 \mathrm{~Pa}$ & $906 \mathrm{~W} \pm 11 \mathrm{~W}$ \\
\hline HEX2 & $3825 \mathrm{~s} \pm 188 \mathrm{~s}$ & $278 \mathrm{~Pa} \pm 11 \mathrm{~Pa}$ & $757 W \pm 22 W$ \\
\hline HEX3 & $2773 s \pm 139 s$ & $275 \mathrm{~Pa} \pm 3 \mathrm{~Pa}$ & $862 W \pm 9 W$ \\
\hline
\end{tabular}

\section{Numerical Methods}

In a series of studies, $\mathrm{Na}$ and Webb (see [1]-[3]) presented their results on the frost formation for simple geometrical configurations. Their approach successfully predicted frosting reference data, however, in order to reduce the related computational cost, Hermes et al. [4] proposed an algebraic modification of the original frost growth and densification model. This model (based on the fundamental principles of energy and mass conservation) has been selected here, and necessary modifications to general Navier-Stokes solver have been implemented in OpenFoam [5]. Figures 12 and 13 show a comparison between the modeled frost creation and the reference experimental data for a flat horizontal cooled surface. The time evolution of the frost thickness and the density agree reasonably well. All frost related correlations (heat and mass transfer coefficients, local velocities and temperatures, etc.) have to be calculated from the flow variables within the zone near the frost surface, and on the other hand flow characteristics within the frost layer have to be solidified. To allow complete flow blockage, frost creation is controlled by local flow characteristics.

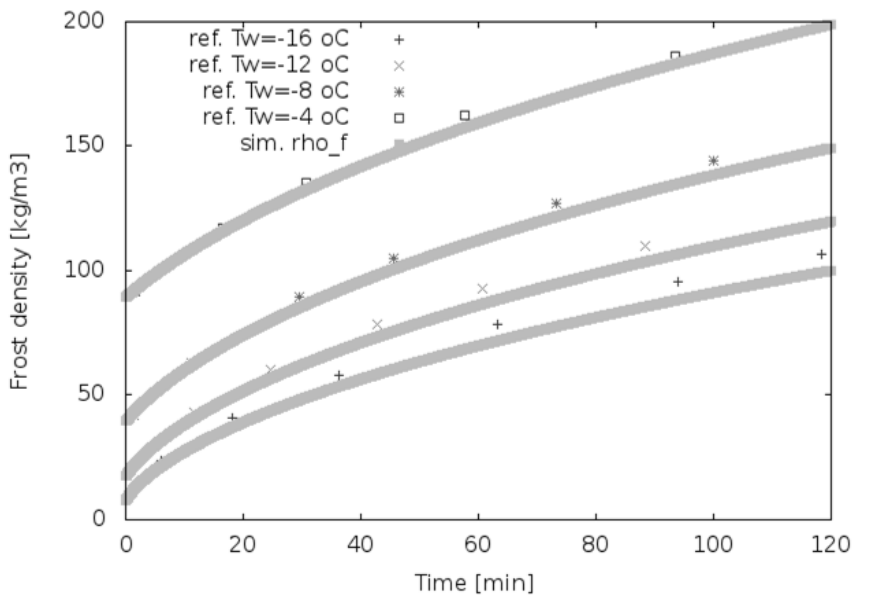

Fig. 12. Frost density for a flat horizontal plate - comparison of numerical and experimental data for several plate temperatures.

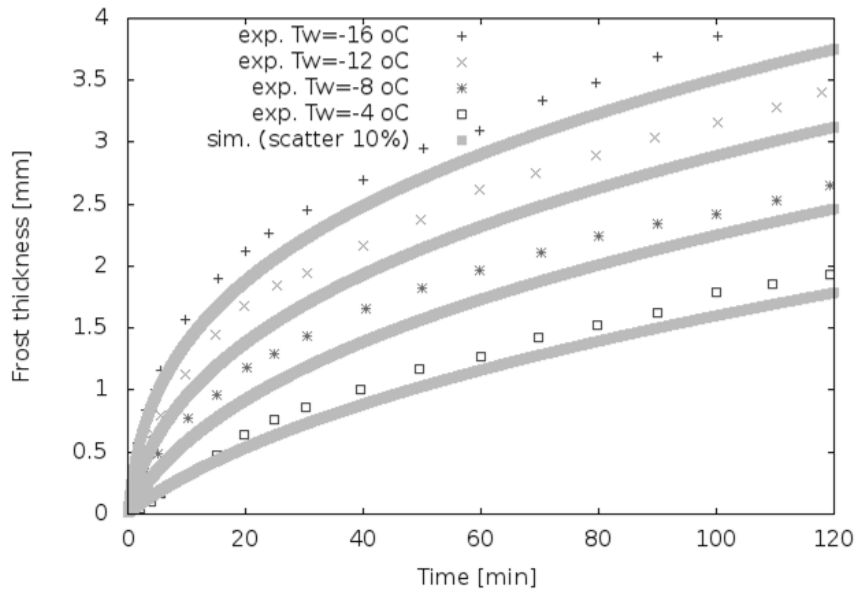

Fig. 13. Frost growth for a flat horizontal plate - comparison of numerical and experimental data for several plate temperatures.

Fig. 14 shows a flat cooled plate example (first four minutes of the frosting process): the initial boundary layer velocity distribution (bottom) is being distorted due to the growth of the solid frost layer (top).
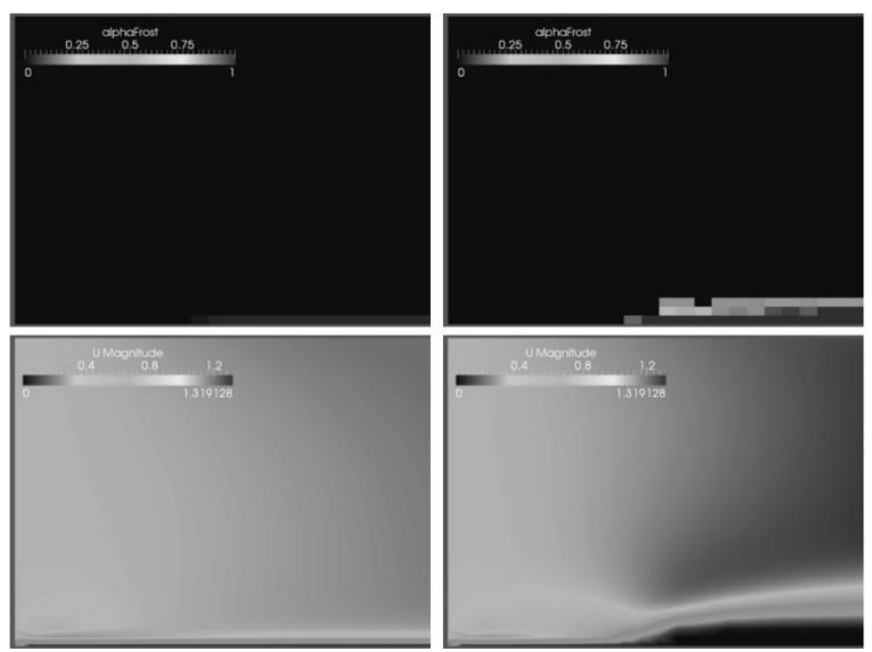

Fig. 14. Ice built up (upper row) and air flow (lower row) over a cooled flat plate. left: initial boundary flow - no ice is built up; right: situation after 4 minutes: the ice has grown and the air flow is distorted.
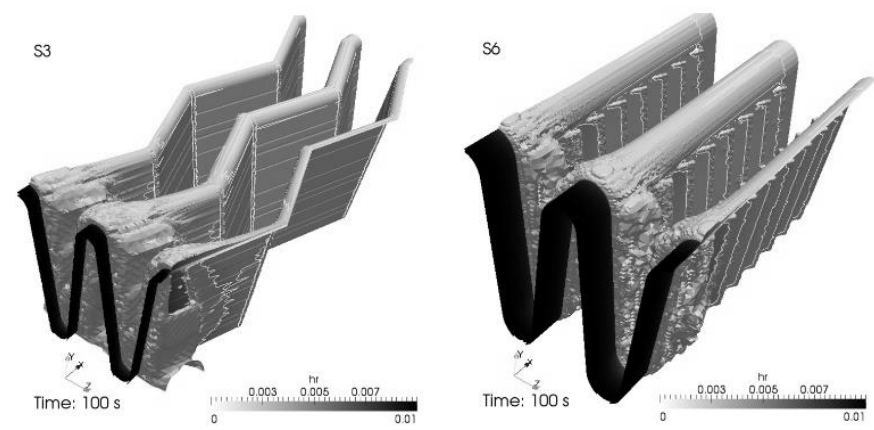

Fig. 15. Ice aggretion patterns on wavy fin (left) and louvered fin (right) configurations after 100 seconds. 
Fig. 15 compares ice aggregation for wavy and louvered fins as an example. High fin density configuration reduced the humidity ratio within the domain, which results in the lower frosting at the fin surface. The louvered fin configuration allows the penetration of the humidity further into the domain, which increases the frosting throughout the geometry.

\section{PROPANE-SIDE OF THE EVAPORATOR}

The refrigerant-side design of the evaporator was separated into sizing the heat exchanger core for its thermal and hydraulic behavior as well as the sizing of the bionic distributor. Crucial constraints, which defined mainly outer dimensions of the core are the above documented fin selection activities and an allowed pressure loss in the diabatic region of the core of less than $1 \mathrm{~K}$ temperature decrease.

\section{A. Sizing of the binary/bionic distributor}

The sizing of the distributor incorporates the development of a hydraulic algorithm, its validation, and a close look at the manufacturing technologies being used for its production. The application of metal sheet design principles for distributors promises highly automatable manufacturing techniques. A detailed introduction on the development of the algorithm is given in Braungardt et al. [21]. Tube and fin height define only
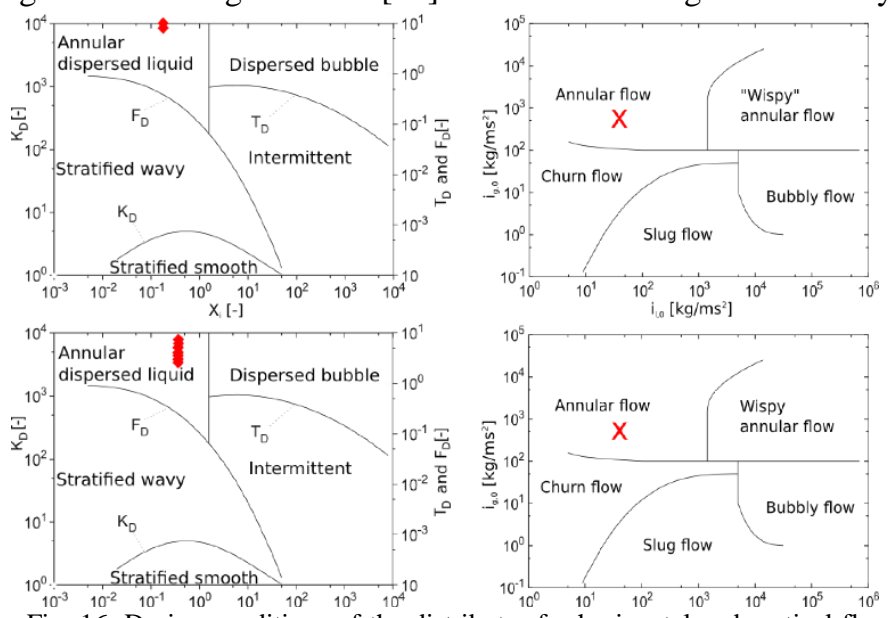

Fig. 16. Design conditions of the distributor for horizontal and vertical flow conditions. Flow regime maps from Taitel and Dukler [19] and Hewitt and Roberts [20] are applied.

the final distance of the outlet channels, whereas a hydraulic algorithm is developed to size outer dimensions and all necessary flow arrangements. Bends of $90^{\circ}$ are applied to have a compact overall height and a chance to apply known pressure drop models for these frequently occurring flow conditions in technical systems. Most crucial design criterion of straight segments is to increase the probability that symmetric flow regime conditions are matched before the bifurcation of the flow takes place. This is mainly annular flow, which was tested for horizontal as well as vertical flow conditions. Main parameter to control the regime development is the mass flux which was sized by applying certain hydraulic diameters and its changes in each bifurcation level. See Fig. 16 in which several matched conditions in different bifurcation levels are shown. Main parameters to locate flow properties within the Taitel-
Dukler map are $\mathrm{F}_{\mathrm{D}}$, the limit between annular and stratifiedwavy flow and $X_{i}$

$$
X=\left(\left(\frac{\Delta p_{R}}{\Delta x}\right)_{l} /\left(\frac{\Delta p_{R}}{\Delta x}\right)_{g}\right)^{0.5}
$$

defined as Lockhard-Martinelli factor [19]. For vertical flow conditions, the Hewitt-Roberts map is applied. Here the

$$
F_{D}=\frac{\dot{m} * \dot{x}}{\left(\left(\rho_{l}-\rho_{g}\right) * \rho_{g} * d * g\right)^{0.5}}
$$

impulse fluxes $i_{g, 0}$ and $i_{1,0}$ define the flow regime areas [20.]

The sized conditions are marked as dots in Fig. 16. The

$$
\begin{gathered}
i_{g, 0}=(\dot{m} * \dot{x})^{2} / \rho_{g}, \\
i_{l, 0}=(\dot{m} *(1-\dot{x}))^{2} / \rho_{l}
\end{gathered}
$$

applied mass flow range was adapted to the project's design constraints from $50 \%$ part load (mass flow $0.0435 \mathrm{~kg} / \mathrm{s}$, vapor quality 0.48 , see lower flow pattern maps in Fig. 16) up to full nominal load (mass flow $0.087 \mathrm{~kg} / \mathrm{s}$, vapor quality 0.3 , see upper flow pattern maps in Fig. 16).

Although flow conditions are important, the unconstrained application leads to outer dimensions of the distributor that by far surpasses the depth of the heat exchanger. The full scale 1to-64 connections for in- and outlets would have a depth of about $759 \mathrm{~mm}$. By recalling its original functionality:

1. Improving phase balancing between all MPE tubes by a robust technique;

2. Decreasing the inner volume of a distributor device by substituting the usually used cylindrical manifolds;

3. Saving efforts in connection technologies compared to the application of commercially available (nozzle) distributors;

a 4-to-64 distributor is chosen to limit its height to less than 335 $\mathrm{mm}$. Fig. 17 shows the fully assembled evaporator. Due to the prototype state, the connection is realized by so- called miniheaders for which two in-line arranged MPE tubes are connected to the 64 outlets of the evaporator. For the market roll-out the direct connection is planned. 


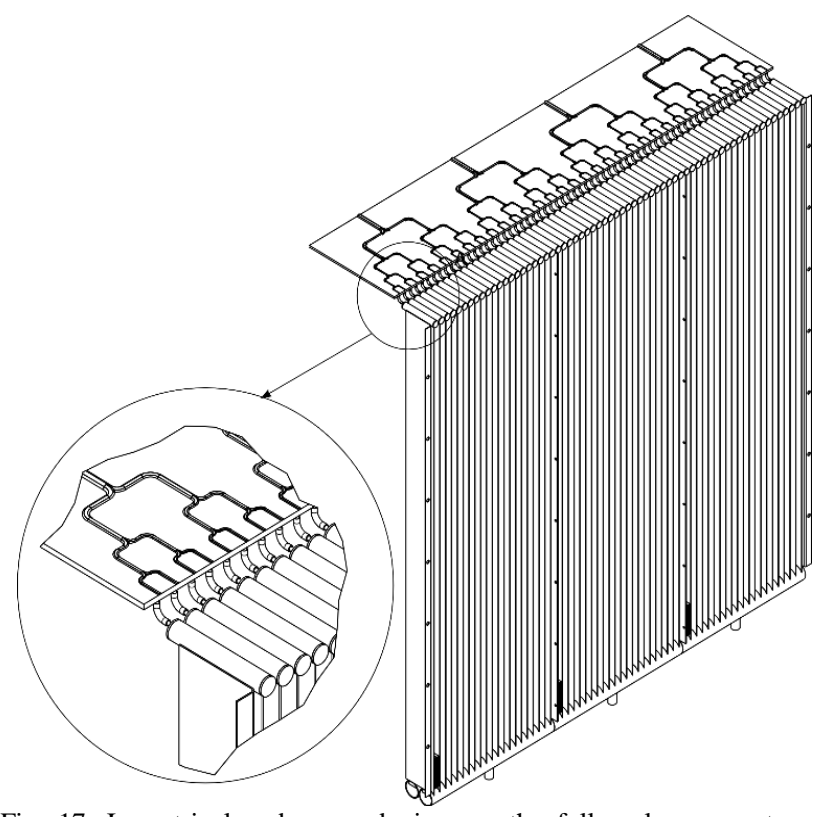

Fig. 17. Isometrical and zoomed view on the full scale evaporator assembly. The zoomed isometrical perspective reveals the chosen connection and the chosen flow arrangement of the distributor. In analogy to large (hollow cylindrical) distributing manifolds small socalled mini-headers connect each distributor outlet to the single pass diabatic heat exchanger core.

TABLE 2:

COMPARISON OF INNER VOLUMES OF APPLICABLE DISTRIBUTION DEVICES

\begin{tabular}{|l|l|}
\hline Distributor type & Inner volume [ml] \\
\hline 2x Venturi 1-to-32 plus feeder lines & 302 \\
\hline $\begin{array}{l}\text { Tube as hollow cylindrical } \\
\text { distributing manifold }\end{array}$ & 4924 \\
\hline $\begin{array}{l}\text { Bionic distributor 4-to-64 with 1-to-4 } \\
\text { pre-distributor and mini-headers }\end{array}$ & 1670 \\
\hline $\begin{array}{l}\text { Bionic distributor 4-to-64 with 1-to-4 } \\
\text { pre-distributor directly mounted }\end{array}$ & 359 \\
\hline
\end{tabular}

The connection to the injection line of the expansion valve and the pre-distribution device is realized by a conventional 1-to-4 nozzle distributor. This allows an optimal trade-off between the original distributor's functionalities described above and the overall assemblage of the evaporator and its incorporation into the subsequent air duct design. The overall manufacturing steps to assemble the full-size evaporator are realized at AKG. A preliminary inner volume comparison is shown in Table 2.

\section{B. Experimental Methods for flow distribution analysis}

In order to allow testing of the distribution quality at different operating conditions, a test bench was developed and built up at Fraunhofer ISE. The test bench is able to provide a flow of any refrigerant at a desired temperature and vapor quality. This

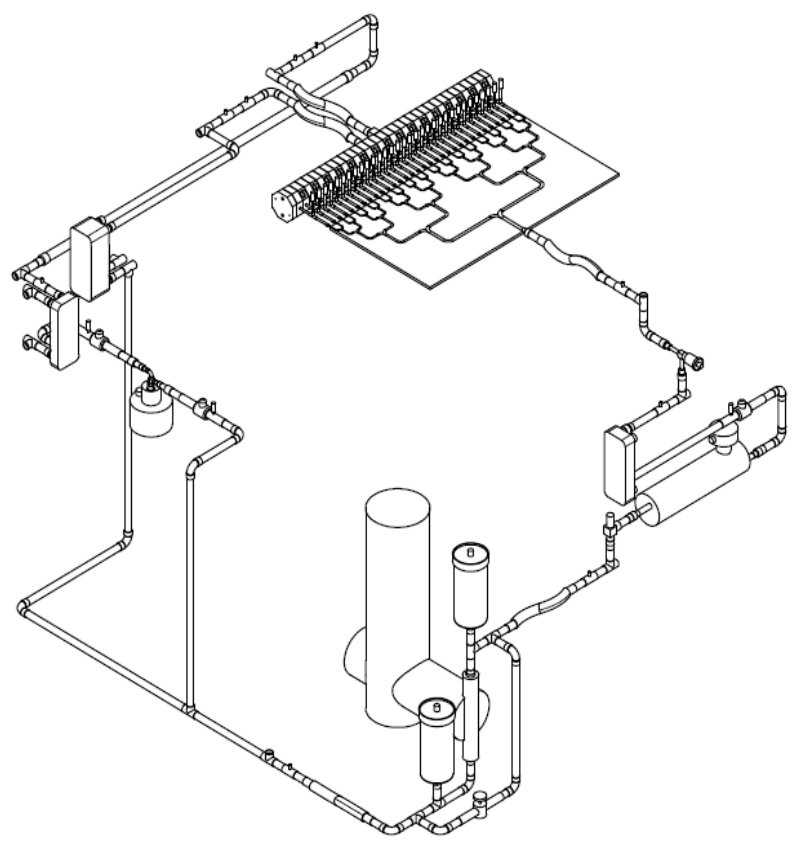

Fig. 18. Test bench for the testing of two-phase fluid distribution.

can then be distributed in the tested device and the mass-flow and the vapor quality can be determined in every exit. Distributors with up to 32 outlets can be tested.

A schematic of the test bench is shown in Fig. 18. A liquid pump raises the pressure of the refrigerant, and then it is heated to a point that it nearly starts boiling. An expansion valve reduces the pressure so that part of the refrigerant evaporates and the desired vapor quality and pressure is achieved. After the distributor, a set of valves allows picking a single exit and measuring its mass flow and determining its vapor quality through an energy balance. Finally, the refrigerant is condensed and returned to the liquid pump.

\section{Experiments with transparent distributor prototypes}

For the first experiments, a transparent prototype was produced. This allows an optical evaluation of the flow-regime and the distribution in the bifurcations. The first prototype is not totally symmetric, but it has some paths folded compared to the others. This was done in order to assess if even more compact geometries are possible with acceptable results in distribution. A schematic of the tested distributor is shown in the following Figure. The resulting distribution is shown in the diagram in Fig. 19. 


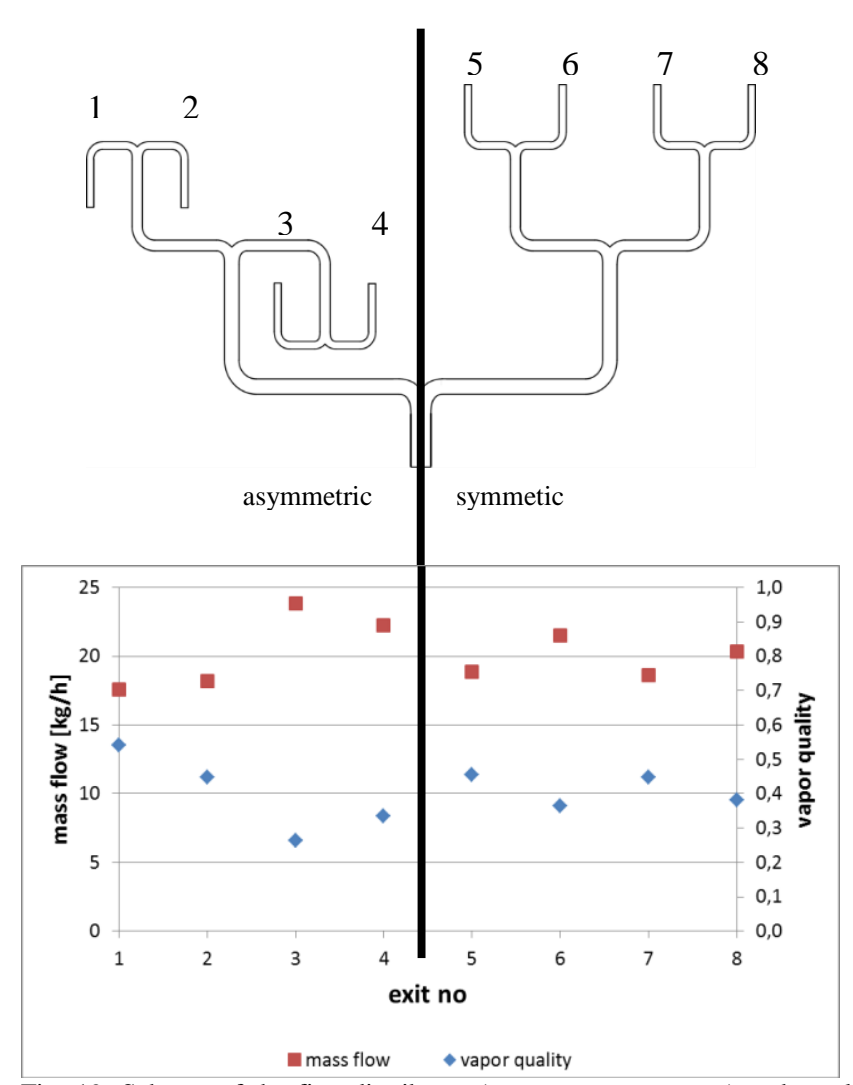

Fig. 19. Schema of the first distributor (transparent prototype) and resulting distribution.

These results show that a more symmetric layout leads to a more uniform distribution. Primarily experimental pressure drop measurements promise further reduction potentials in the hydraulic diameter and thus the inner volume.

\section{Experiments with formed distributor}

The distributor is manufactured as a one-side flat device. Channel structures for the flow distribution require precise forming technologies to keep not-formed areas as plane as possible to simplify the subsequent vacuum brazing of the distributor. The forming as well as the mechanical sizing was realized at Fraunhofer IWU. It included several FEM simulations for the opposed channel pressure resistance and forming processes, the tool design and manufacturing, the production of tailored blanks as well as the distributor manufacturing.

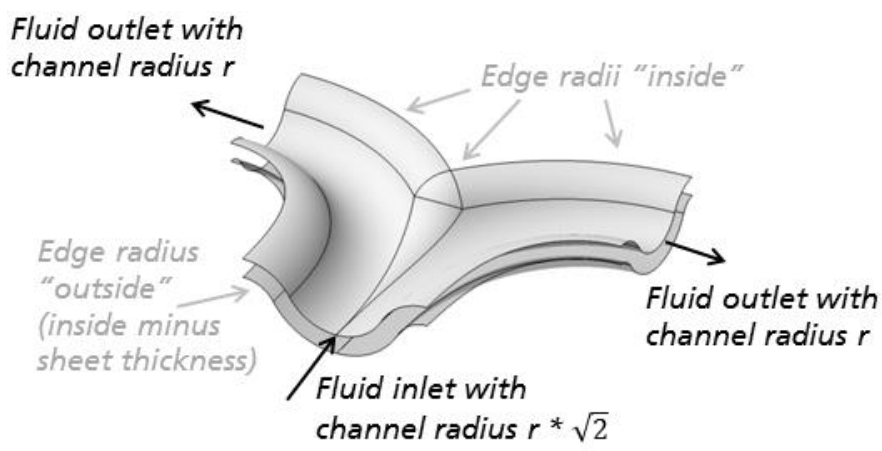

Fig. 20. Radii at in- and outlet of an exemplary bifurcation as it is applied for the tailored blank metal sheet forming process.
Two different forming concepts were applied to match the desired boundary conditions:

1. Sequential moulding of metal sheets with several thicknesses (tailored blanks).

2. Hydroforming of the full-size distributor with a single sheet thickness.

EN AW 1050 is used as sheet material because of its compatibility with vacuum brazing and availability in several sheet thicknesses. Tailored blanks were produced by CNC laser welding before moulding took place. The geometry was adapted to the needs of the hydraulic performance sized by Fraunhofer ISE and the needs of the mechanical constraints defined by the material properties. To allow a homogeneous channel system within a tailored blank the bifurcation geometry and the ratio of their channel to edge radii (minimum $=$ sheet thickness) need to be constant, see Fig. 20 for details.

The second forming alternative with the single sheet thickness allows applying constant, small channel edge radii at the price of slightly varying bifurcation geometry at each distribution level. This means that the larger the fluid channels become, the closer they are to a perfect round shape. Therewith, theoretically decreasing wall thickness to channel diameter ratio and the according pressure resistance loss can be compensated.

With the preliminary planned full-size 1-to-64 distributor three different thicknesses (1, 2 and $4 \mathrm{~mm}$ ) were necessary to fulfill the requirements for sufficiently high pressure resistance whereas the compromise of the 4-to-64 distributor allows working with only the two smaller sheets.

Burst pressure tests for the moulded tailored blank distributor were already performed at AKG to ensure that operation pressure ranges as valid for R290 can safely be reached. For the already formed 1 and $2 \mathrm{~mm}$ sheets burst pressures of about 75 and 95 bar, respectively, are reached.

The 4-to-64 single thickness distributor concept allows realizing the hydroforming with only $1 \mathrm{~mm}$ sheet thickness which results in significant savings in material cost and manufacturing expenses.

\section{E. Numerical methods}

The application of CFD simulation was driven by two motivations. In the first place, it was done to cross-validate the scarce two-phase pressure drop models for bends but especially for bifurcations before validated experimental data were available, and, secondly, to understand re-development effects on flow conditions after induction of secondary flow due to bends and bifurcations. This latter aspect is very crucial to understand the minimum distance before bifurcations can be placed again. This influences largely the overall size (compactness) of the distributor. Both CFD simulations were performed in OpenFOAM [5]. A mesh sensitivity analysis was performed preliminary to the two simulations.

The pressure drop cross validation was realized with RANS simulations. Six different operation conditions (cases) were applied. 
TABLE 3

EXEMPLARY DESIGN CONDITIONS SIMULATED WITH RANS IN OPENFOAM

\begin{tabular}{|c|c|c|c|c|c|c|}
\hline Case & $\begin{array}{c}\mathrm{X} \\
{[\%]}\end{array}$ & $\begin{array}{c}\mathrm{G} \\
{\left[\mathrm{kg} / \mathrm{m}^{2} \mathrm{~s}\right]}\end{array}$ & $\begin{array}{c}\mathrm{u}_{\mathrm{l}} \\
{[\mathrm{m} / \mathrm{s}]}\end{array}$ & $\begin{array}{c}\mathrm{u}_{\mathrm{g}} \\
{[\mathrm{m} / \mathrm{s}]}\end{array}$ & $\begin{array}{c}\mathrm{Q} \\
{[\mathrm{kW}]}\end{array}$ & $\begin{array}{c}\mathrm{T}_{\mathrm{amb}} \\
{\left[{ }^{\circ} \mathrm{C}\right]}\end{array}$ \\
\hline 2 & 0.18 & 420.3 & 0.69 & 9.64 & 24 & 0 \\
\hline 5 & 0.53 & 355.7 & 0.32 & 22.56 & 12 & 0 \\
\hline
\end{tabular}

The used solver was interFOAM as transient solver with VOF. The system was considered as incompressible fluidic system, adiabatic with no phase change. The applied turbulence model was k- $\omega$-SST [23]. Fig. 21 shows the segmented bifurcation. Fig. 23 explains in detail the results of one of the simulated cases listed in Table 3. Box- and violin plots are used to represent the transient pressure development. Results from low-dimensional pressure drop models are included as black dots. By comparing the upper with the lower graph it can be seen that CFD and pressure drop model comparison is more similar for higher vapor qualities.

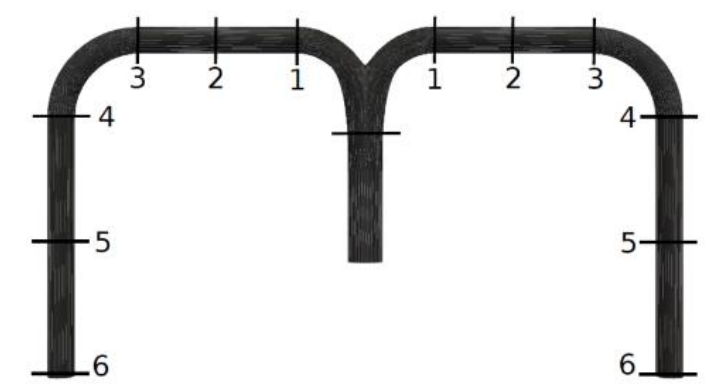

Fig 21. Location of slices at which pressures were calculated for the pressure drop analysis in Figure 23.

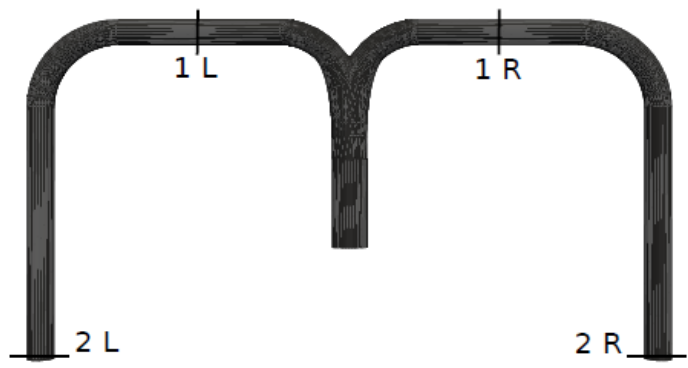

Fig. 22. Map of slice locations for LES simulation.

The flow regime development was simulated by LES. The used solver is compressibleinterFOAM with transient conditions and VOF. Again the system is considered as adiabatic without phase change. Turbulance models applied are dynamic Smagorinsky [28] and K-equation [29].
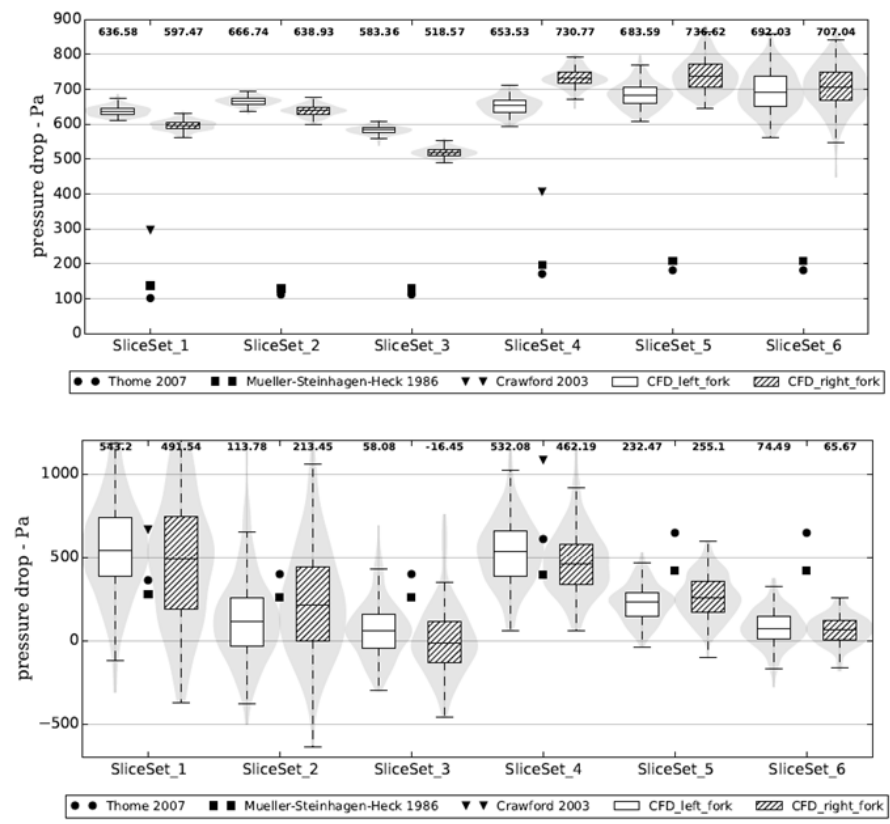

Fig 23. Box plot graphs for RANS simulations at vapor qualities of case \#2 (upper graph) and case \#5, see Table 3 for case details. Each slice set represents the pairwise pressures which were calculated in the defined locations shown in Fig. 20.

Slices are located at 4 points, see Fig. 22.

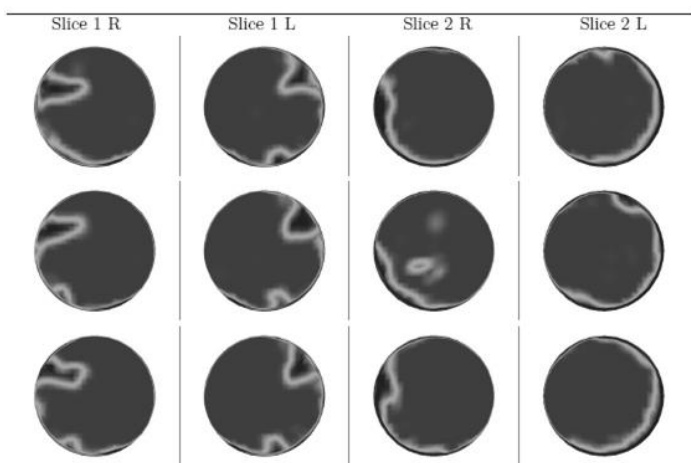

Fig. 24. Phase boundaries at different time steps at slices $1 \mathrm{~L}, 1 \mathrm{R}, 2 \mathrm{~L}, 2 \mathrm{R}$.

In Fig. 24 phase boundaries can be viewed. Directly downstream of the bifurcation the impingement effect and the disturbance of the annular flow regime is obvious. The slices are arranged so $1 \mathrm{R}$ and $2 \mathrm{R}$ (see Fig. 22) show the positive direction of the centrifugal forces on the left side, whereas $1 \mathrm{~L}$ and $2 \mathrm{~L}$ show the same on the right side. The impact of the centrifugal force in slice \#2 L/R levels these propagating waves continuously out. However, a slight asymmetric distribution of the annular ring does not vanish and runs into the next bifurcation level.

\section{SUMMARY AND CONCLUSIONS}

Using the wind tunnel facilities placed in a climate chamber, the icing characterization of different fin geometries and surface structures (coatings) is possible. With the distributor test bench new and existing flow distributing technologies can be characterized. For the numerical analysis OpenFOAM was successfully used and a frosting model was implemented in the open-source Navier-Stokes solver OpenFoam. 
Both experimental and numerical techniques are feasible for the pre-selection of fin types. For the sizing of plane distributors the numerical design needs to be further validated to allow sizing calculations. Several techniques are readily developed to support any evaporator design. Some of the methods (PIV, Shadowgraphy, Video analysis, CFD) could also be used for investigations in the climate chambers and test benches on full scale HEXs in heat pumps.

Fin geometry has an influence on the icing properties and the overall mean heat transfer. Wavy fins seem to be a good compromise between a good heat transfer and a proper icing time. Blocking takes place at the inlet area, which is supported both by experiments and numerical simulations.

The bionic distributor fulfills necessary burst pressure tests. The distribution quality of the transparent prototypes and its inner volume significantly improves the performance in comparison to known cylindrical distributing manifolds.

First experimental validation measures for the applied pressure drop models promises even further potential in hydraulic diameter reduction which allows smaller inner volumes.

Next steps include some final steps for the full size forming of the distributor at Fraunhofer IWU, the brazing of the full-size distributor, further burst pressure tests for the hydroformed (overall thickness is then only $1 \mathrm{~mm}$ ), finishing pressure drop model validation and the full assemblage of the evaporator at AKG, comparison between MPE tube heat exchangers and conventional finned-tube heat exchangers for frosting and defrosting at AIT and Fraunhofer ISE and finally the experimental characterization of the full-size distributorevaporator package with R290 as refrigerant.

\section{ACKNOWLEDGEMENTS}

This project is funded by the European Commission within the 7th Framework Programme (FP7) - grant agreement No FP7-Energy-2012-308816. Part of the work at AIT has also been performed supported by the Austrian Research Funding Agency (FFG) and Klima-Energy-Fonds (Project Numbers 82018, 829964, 834684).

\section{REFERENCES}

[1] B. Na, R. Webb. 2003, A fundamental understanding of factors affecting frost nucleation, International Journal of Heat and Mass Transfer 46: 3797-3808. http://dx.doi.org/10.1016/S0017-9310(03)00194-7

[2] B. Na, R. Webb. 2004, Mass transfer on and within a frost layer, International Journal of Heat and Mass Transfer 47: 899-911. http://dx.doi.org/10.1016/j.ijheatmasstransfer.2003.08.023

[3] B. Na, R. Webb. 2004, New model for frost growth rate, International

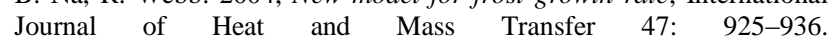
http://dx.doi.org/10.1016/j.ijheatmasstransfer.2003.09.001

[4] C. J. L. Hermes, R. O. Piucco, J. R. Barbosa Jr., C. Melo. 2009, A study offrost growth and densification on flat surfaces, Experimental Thermal and Fluid Science 33: 371-379. http://dx.doi.org/10.1016/j.expthermflusci.2008.10.006

[5] H. G. Weller, G. Tabora, H. Jasak, C. Fureby. 1998, A tensorial approach to computational continuum mechanics using object-oriented techniques, Computers in Physics 12: 620 - 631. http://dx.doi.org/10.1063/1.168744

[6] M. Albert, R. Sahinagic, L. Gasser, B. Wellig, K. Hilfiker, Prediciton of ice and frost deformation in the fin tube evaporators for Air/Water heat pump, 9th International IEA Heat Pump Conference, 2008

[7] M.W. Browne, P.K. Bansal, An overview of condensation heat transfer on horizontal tube bundles, Applied Thermal Engineering 6 (19), p. 565 594, 1999. http://dx.doi.org/10.1016/S1359-4311(98)00055-6
[8] A. Cavallini, G. Censi, D. Del Col, L. Doretti, G.A., Longo, L. Rossetto, C. Zilio, Condensation inside and outside smooth and enhanced tubes - a review of recent research, International Journal of Refrigeration (4) 26, p. 373-392, 2003. http://dx.doi.org/10.1016/S0140-7007(02)00150-0

[9] L. Cremaschi, E. Moallem, D. E. Fisher, T. Hong. S. Padhmanabhan, Frosting Performance of Fin- and-Tube Evaporators with Small Copper Tubes Diameter, International Refrigeration and Air Conditioning Conference, 2012

[10] C. L. Fitzgerald, A. Briggs, J. W. Rose, H. Sheng Wang, Effect of vapor velocity on condensate retention between fins during condensation on lowfinned tubes, International Journal of Heat and Mass Transfer 4 (55), p. 1412 1418, 2012. http://dx.doi.org/10.1016/j.ijheatmasstransfer.2011.09.063

[11] N. Hewitt, M. Jun Huang, Defrost cycle performance for a circular shape evaporator air source heat pump, International Journal of Refrigeration 3 (31), p. 444-452, 2008. http://dx.doi.org/10.1016/j.ijrefrig.2007.07.010

[12] L. E. Kollar, M. Farzaneh, Wind-tunnel investigation of icing of an inclined cylinder, International Journal of Heat and Mass Transfer 5 (53), p. 849-861, 2010. http://dx.doi.org/10.1016/j.ijheatmasstransfer.2009.11.039

[13] P. J. Marto, Film Condensation Heat-Transfer Measurements on Horizontal Tubes - Problems and Progress, Experimental Thermal and Fluid Science 4 (5), p. 556-569, 1992. http://dx.doi.org/10.1016/08941777(92)90042-4

[14] E. Moallem, L. Cremaschi, D. E. Fisher, S. Padhmanabhan, Experimental measurements of the surface coating and water retention effects on frosting performance of microchannel heat exchangers for heat pump systems, Experimental Thermal and Fluid Science 0 (39), p. 176-188, 2012. http://dx.doi.org/10.1016/j.expthermflusci.2012.01.022

[15] V. Payne, D.L. O'Neal, Defrost cycle performance for an air-source heat pump with a scroll and a reciprocating compressor, International Journal of Refrigeration 2 (18), p. 107-112, 1995. http://dx.doi.org/10.1016/0140-7007(95)93893-O

[16] C.C.Wang, Y. J. Chang, Y. T. Lin, Sensible heat and friction characteristics of plate fin-and-tube heat exchangers having plane fins, International Journal of Refrigeration 4 (19), p. 223-230, 1996. http://dx.doi.org/10.1016/0140-7007(96)00021-7

[17] C. C. Wang, W. L. Fu, C. T. Chang, Heat transfer and friction characteristics of typical wavy fin-and-tube heat exchangers, Experimental Thermal and Fluid Science 2 (14), p. 174-186, 1997. http://dx.doi.org/10.1016/S0894-1777(96)00056-8

[18] C. C. Wang, C .J. Lee, C. T. Chang, S. P. Lin, Heat transfer and friction correlation for compact louvered fin-and-tube heat exchangers, Internation Journal of Heat and Mass Transfer 11 (42), p. 1945-1956, 1999. http://dx.doi.org/10.1016/S0017-9310(98)00302-0

[19] Y. Taitel, A. E. Dukler, A model for predicting flow regime transitions in horizontal and near horizontal gas liquid flow, AIChE J 22 (1), p. 47-55, 1976. http://dx.doi.org/10.1002/aic.690220105

[20] G. F. Hewitt, D. N. Roberts, Studies of two-phase flow patterns by simultaneous $X$-ray and flash photography, AERE-M (Atomic Energy Research Establishment, Harwell, England), Technical Report, 1969

[21] S. Braungardt, N. Schultz, R. Langner, T. Oltersdorf. 2012, Tree-Shaped Two-Phase Fluid Distributor for microchannel heat exchangers used as evaporator, IIR $3^{\text {rd }}$ Refrigerant Charge Reduction in Refrigerating Systems, UPV, Valencia, Spain

[22] F. Pfender, CFD-Simulation von Zweiphasenströmungen in einem fraktalen Kältemittelverteiler, Master Thesis, TU Berlin, 26 $6^{\text {th }}$ November 2014

[23] F. R. Menter, Two-equation eddy-viscosity turbulence models for engineering applications, AIAA Journal 32 (8), p. 1598-1605. http://dx.doi.org/10.2514/3.12149

[24] N. M. Crawford, G. Cunningham, P. L. Spedding, Prediction of pressure drop for turbulent fluid flow in 90-degree bends, J Proc Mech Eng, Part E 217 (3), p. 153-155, 2003

[25] D. Chisholm, Pressure gradients due to friction during the flow of evaporating two-phase mixtures in smooth tubes and channels Int J Heat Mass Trans 16 (2), p. 347-358, 1973

[26] J. R. Thome, Wolverine Data Handbook III, URL: http://www.wlv.com/heat-transfer-databook/

[27] H. Müller-Steinhagen, K. Heck, A simple friction pressure drop correlation for two-phase flow in pipes, Chem Eng Proc: Process Intensification 20 (6), p. 297-308

[28] G. Massimo, U. Piomelli, P. Moin und William H. Cabot (1991), A dynamic subgrid-scale eddy viscosity model, Physics of Fluids A: Fluid Dynamics 3.7, p. 1760

[29] A. Yoshizawa, K. Horiuti, A statistically-derived subgrid scale kinetic energy model for the large eddy simulation of turbulent flows, J Phys Soc Jap 54 (8), p. 2834-2839 